\title{
SIMULATION OF A SOLAR DOMESTIC WATER HEATING SYSTEM, WITH DIFFERENT COLLECTOR EFFICIENCES AND DIFFERENT VOLUMEN STORAGE TANKS
}

\author{
Delfín Silió Salcines, Carlos Renedo Estébanez and Valentín Castañera Herrero \\ Department of Electrical Engineering, \\ E.T.S.I.I. yT., Cantabria University \\ Avda. Los Castros s/n, 39005 Santander (Spain) \\ Phone: +34 942 201370, fax: +34 942 201385, e-mail: siliod@unican.es, renedoc@unican.es, castanev@unican.es
}

\begin{abstract}
This paper shows the modeling and dynamic simulation, of a domestic solar water heating installation.

The results of simulations performed on an annual basis for a solar system, operated in Santander (Spain), which provides hot water for a family (four persons) are presented. The installation consists in a solar flat collector, a water storage tank, a source of auxiliary energy, and a device for blending water.

The mathematical model is used to evaluate the annual variation of the solar fraction respect to the volume of the storage tank, demand hot water temperature required, difference of this temperature and preset storage tank water temperature, and consumption profile of the domestic hot water demand.

The results for a number of designs with different storage tank volumes, show that the systems with greater volume yield higher solar fraction values. However, when a larger storage tank volume is used, the solar fraction is less sensitive to a variation of these operation parameters. The results of this simulation may be used to design a solar collector system.
\end{abstract}

\section{Key word}

Solar collector, storage tank, modelling, simulation.

\section{Introduction}

During the last years of the twentieth century, extensive efforts to alleviate global warming of the earth caused by emission of carbon dioxide in atmosphere have been undertaken. These emissions are generated by intensive burning of fossil fuels in order to satisfy the growing energy needs of humanity. The $\mathrm{CO}_{2}$ emissions may be mitigated when part of energy needs are satisfied by using renewable energy sources, such as solar energy, instead of fossil fuels. One of the most classical way to use the solar energy is making domestic hot water
(DHW). Solar systems for DHW production should be optimally designed and operated. This way, the energy effectiveness of these systems are often investigated, by using experiments or through modelling and simulations $[1,2]$. This paper shows the results of the computer simulations carried out in order to investigate the effectiveness of a particular type of the solar system. Such a system should consist of two main elements as solar collector and a storage tank. The mathematical model takes into account daily and yearly variations of ambient temperature and solar radiation. This mathematical model is used to develop a specific simulation software. The simulations performed by using this software, give the solar fractions for several system designs with different solar colectors and different storage volumes.

\section{System configuration}

A schematic diagram of the solar system modelled is shown in Fig. 1. It consists of a flatplate solar collector, a water-storage tank, a heat exchanger, a source of auxiliary energy, and a water-mixing device. The solar collector collects solar energy and heats the circulating water that flows through it. The circulating water from the collector enters the heat exchanger installed inside the storage tank where it gives its heat to the storage tank water and then returns to the solar collector where it is heated again by solar energy. The storage tank contains water that accumulates heat obtained from the heat exchanger. The cold water enters the storage tank at the bottom, and the supply hot water exits from the top. The supplied hot water may be cooled before directed to the house for use $\left(45^{\circ} \mathrm{C}\right)$. Cooling is performed with the mixing device by adding cold water from the mains as shown in Fig. 1. An electric resistance heater is used for auxiliary heating when the temperature of the water in the storage tank is lower than $60^{\circ} \mathrm{C}$. 


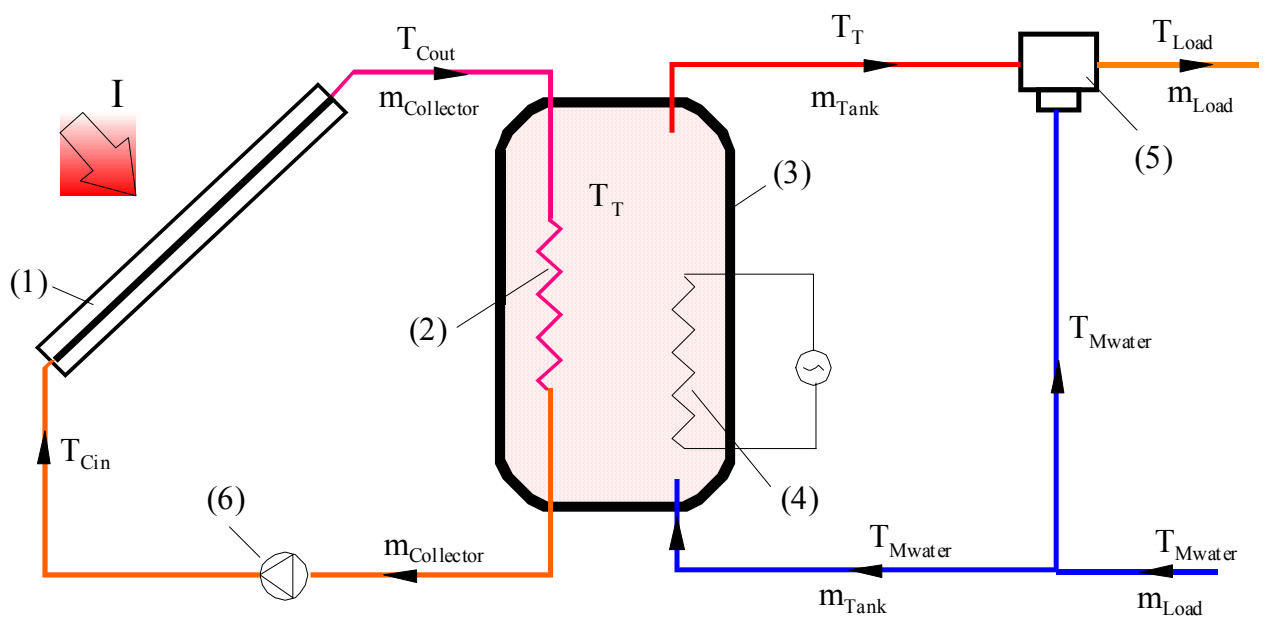

Fig. 1. Schematic diagram of the DHW system: 1- solar collector; 2 - solar heater; 3 - tank; 4 - electric heater; 5 - mixing device; 6 - water pump.

\section{The simulation program}

The performance of the systems was modelled by a simulation program written in MATLAB programming language developed at the University of Cantabria.

The program calculates the solar gain for the specified system, based on the insolation, the ambient temperature, the latitude, the parameters specifying the solar collector system, the volume of storage tank, the total energy demand of heat water and their daily and annual load profiles. The time step for the calculation is set to $1 \mathrm{~h}$, the results are given with monthly resolution. The relations used for modelling the solar system are presented in sections (A) and (B), for that, we have used the mathematical model of Ref. [3,4].

The typical CPU consumption of a 1 year calculation with 1 -h time step is a few seconds using a single $400 \mathrm{MHz}$ PC. The simulation program is thus an efficient tool to study the effects of various desing parameters.

\section{A. Mathematical model}

During a particular instant, the temperature of the circulated water at the solar collector exit is calculated from the equation:

$$
T_{\text {Cout }}=T_{\text {Cin }}+\frac{I \eta_{C} S_{C}}{\left(\dot{m} C_{p}\right)_{\text {Collector }}}
$$

The collector efficiency may in the first order be approximated by a linear function in $\left(T_{C i n}-T_{a m b}\right) / I$ :

$$
\eta_{C}=F_{R}(\tau . \alpha)-\left(F_{R} U_{C}\right) \frac{T_{C i n}-T_{a m b}}{I}=a-b \frac{\Delta T}{I}
$$

and the rate of addition of energy from the collector is:

$$
\dot{Q}_{\text {Collector }}=I S_{C} \eta_{C}
$$

The heat exchanger efficiency $(P)$, from the circulated water to the storaged water is calculated by:

$$
P=\frac{T_{\text {Cout }}-T_{\text {Cin }}}{T_{\text {Cout }}-T_{T}}
$$

The heat losses at the tank is given by:

$$
Q_{\text {loss }}=\left(S_{T} U_{T}\right)\left(T_{T}-T_{a m b^{\prime}}\right)
$$

The energies removal to the tank and supply to the load can be expressed as:

$$
\begin{aligned}
& \dot{Q}_{\text {removal }}=\dot{m}_{\text {Tank }}\left(C_{p}\right)_{W}\left(T_{T}-T_{\text {Mwater }}\right) \\
& \dot{Q}_{\text {Load }}=\dot{m}_{\text {Load }}\left(C_{p}\right)_{W}\left(T_{\text {Load }}-T_{\text {Mwater }}\right)
\end{aligned}
$$

From de equations (6) and (7) we obtain the relationship between tank and load flow rates:

$$
\dot{m}_{\text {Tank }}=\dot{m}_{\text {Load }} \frac{\left(T_{\text {Load }}-T_{\text {Mwater }}\right)}{\left(T_{T}-T_{\text {Mwater }}\right)}
$$


The auxiliary heater is used when the temperature of the water in the storage tank $\left(T_{T}\right)$ is lower than $60{ }^{\circ} \mathrm{C}$; in this case the auxiliary energy is calculated by:

$$
Q_{\text {Aux }}=M_{\text {Tank }}\left(C_{p}\right)_{\text {Water }}\left(60-T_{T}\right)
$$

and energy balance on the tank yields:

$$
M_{\text {Tank }}\left(C_{p}\right)_{\text {Water }} \frac{d T_{T}}{d t}=\dot{Q}_{\text {Collector }}-\dot{Q}_{\text {Losses }}-\dot{Q}_{\text {Load }}
$$

This equation is integrated over time to determine the longterm performance of the storage unit and the solar process. We solving that rewriting in finite difference form and solving for the tank temperature at the end of a time increment ( 1 hour). The temperature at the end of an hour from that at the beginning, assuming that temperatures do not change during the hour.

The performance of installation is evaluated by calculating the annual solar fraction $(f)$ by:

$$
f(\%)=100 \frac{\left(Q_{\text {Load }}\right)_{\text {Yearly }}-\left(Q_{\text {Aux }}\right)_{\text {Yearly }}}{\left(Q_{\text {Load }}\right)_{\text {Yearly }}}
$$

\section{B. Simulation parmeters}

The simulations are performed for the solar installation employing three different solar collectors. The coefficients characterising of this are:

$$
\begin{array}{ll}
\text { Colector (1): } a=0,81 & b=3,5 \mathrm{Wm}^{-2} \mathrm{~K}^{-1} \\
\text { Colector (2): } a=0,81 & \mathrm{~b}=4 \mathrm{Wm}^{-2} \mathrm{~K}^{-1} \\
\text { Colector (3): } \mathrm{a}=0,81 & \mathrm{~b}=4,5 \mathrm{Wm}^{-2} \mathrm{~K}^{-1}
\end{array}
$$

The efficiency curves of colectors are shown in Fig. 2

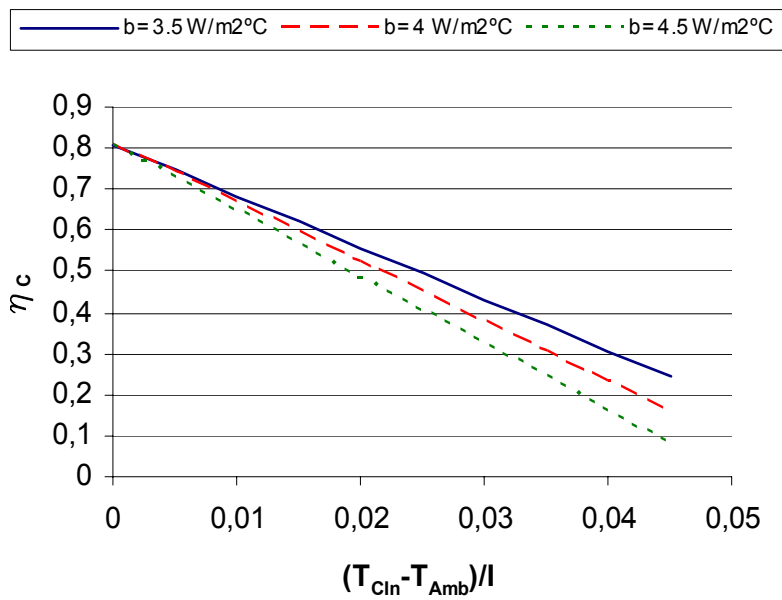

Fig. 2. Efficiency of colectors
The simulation have been done with areas of 6 and $8 \mathrm{~m}^{2}$ respectively, and with a consumption of $2401 /$ day .

The program can give results on a daily or an annual basis. For the simulations performed on an annual basis, the storage tank volume is investigated in the range from 50 to $300 \mathrm{l}$, and required demand water temperature at $45^{\circ} \mathrm{C}$. The mains temperature considered is different each month and corresponds to the mean monthly water supply temperature.

The thermal load, although the hot water demand is subject to a high degree of variation from day to day consumer, it is impractical to use anything but a repetitive load profile. This is not quite correct during the summer period, where the consumption pattern is somewhat higher. However, during this period, the temperature requirement for hot water is not as high as during winter. Consequently, the total thermal energy requirement is reasonably constant throughout the year.

The profile of a daily DHW consumption is taken to be the same for every day in the year. Two types of profiles are considered in the present analysis; constant and variable. The variable profile of the daily consumption, it's shown in Fig. 3.

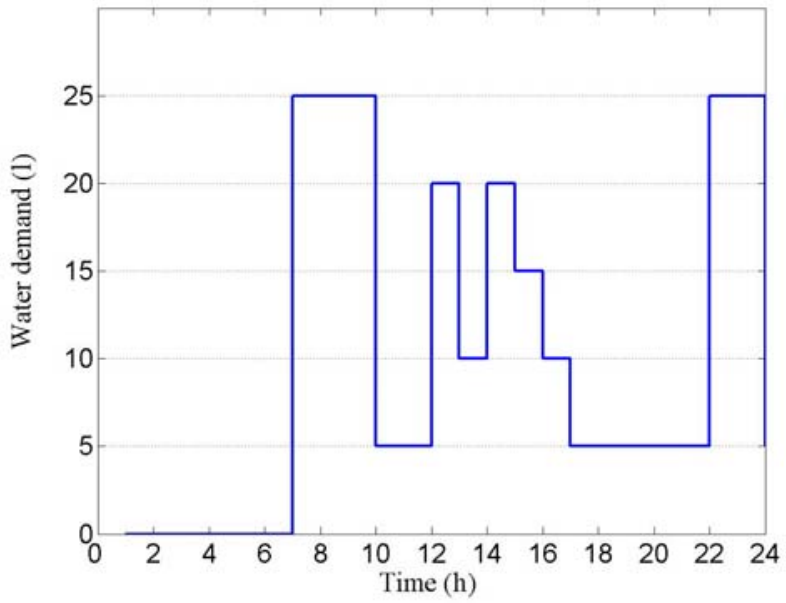

Fig. 3. Variable profile of daily consumption of the DHW

The solar radiation values for Santander (Spain), have been used for the simulations. This values are shown in Fig. 4.

For the case of hourly ambient temperature the following model has been applied.

$$
\left(T_{a m b}\right)_{h}=\left(T_{a m b}\right)_{\text {mean }}+A\left(\cos \frac{\pi}{12} t-\frac{5 \pi}{4}\right)
$$




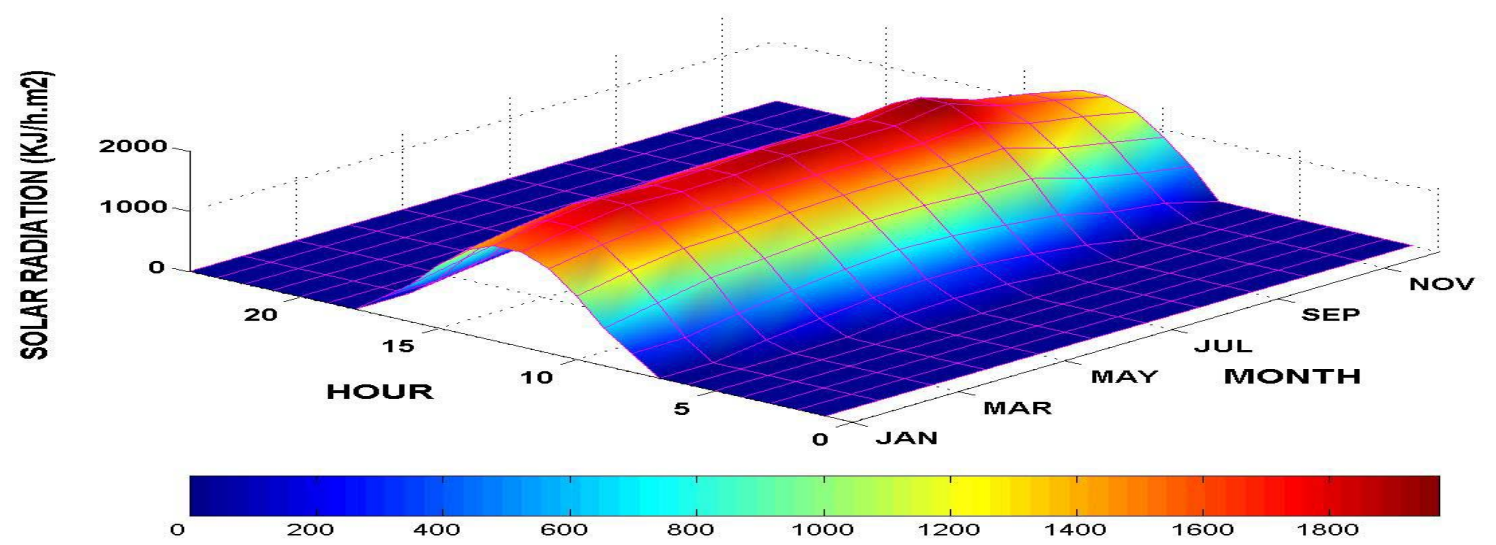

Fig. 4. Intensity of incident solar radiation in Santander (slope $45^{\circ}$, south orientation)

\section{Results}

The simulation results are shown in Figs. 5-11.

The performance of a system with a solar collector case (1), collector area of $8 \mathrm{~m}^{2}$, storage tank of $150 \mathrm{l}$, required DHW temperature of $45^{\circ} \mathrm{C}$, and a variable consumption profile for typical summer and winter days are shows in Fig. 5 and Fig. 6 respectively. As can be seen, in typical summer day, the storage tank temperature rises from about 61 to about $91^{\circ} \mathrm{C}$ whereas the maximum value of solar flux during the day is about $525 \mathrm{~W} / \mathrm{m}^{2}$. Auxiliary energy is not neccesary.

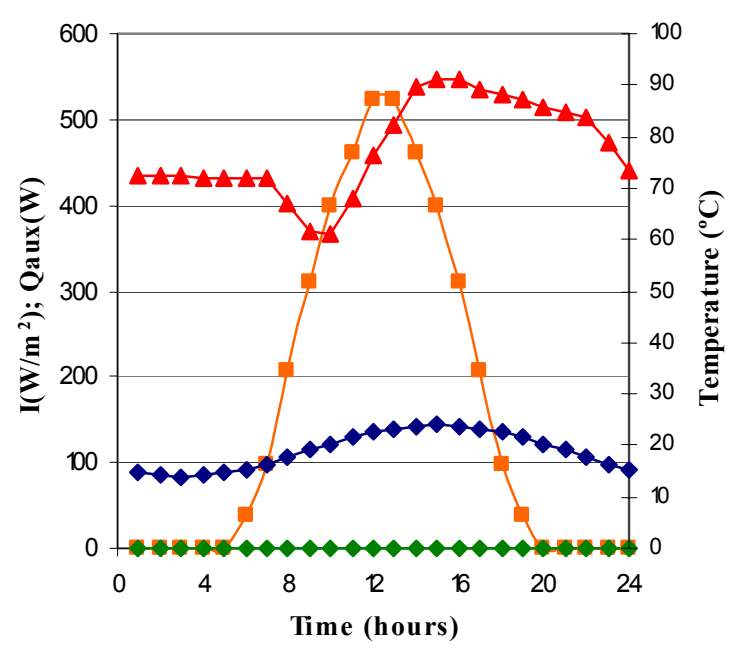

$\longrightarrow$ Solar intensity $(\mathrm{I})$
$\longrightarrow$ Stored water temperature $\longrightarrow$ Auxiliary power (Qaux)
$\longrightarrow$ Ambient temperature

Fig. 5. Performance of solar system for one typical summer day
In typical winter day, the storage tank temperature rises from about 60 to about $72^{\circ} \mathrm{C}$. The maximum value of solar flux during the day is about $435 \mathrm{~W} / \mathrm{m}^{2}$. Auxiliary energy is required from 7 to 9 and from 22 to 23 hours.

Figures 7, 8 and 9 shows the tank temperatures, the monhtly auxiliary energy required and efficiency colector, respectively, for $8 \mathrm{~m}^{2}$ collector area, 1501 storge tank collector case (1), and variable consumption profile.
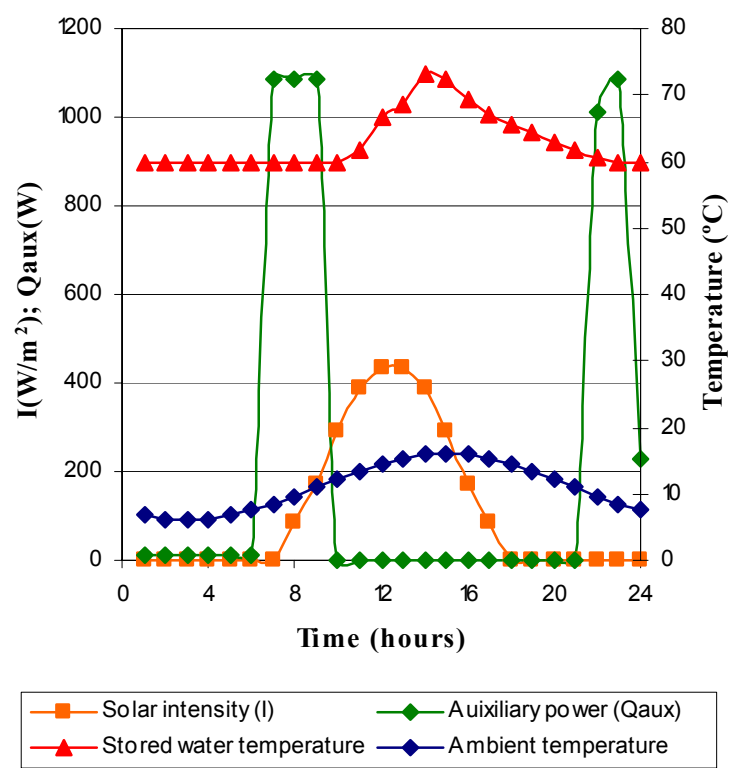

Fig. 6. Performance of solar system for one typical winter day 


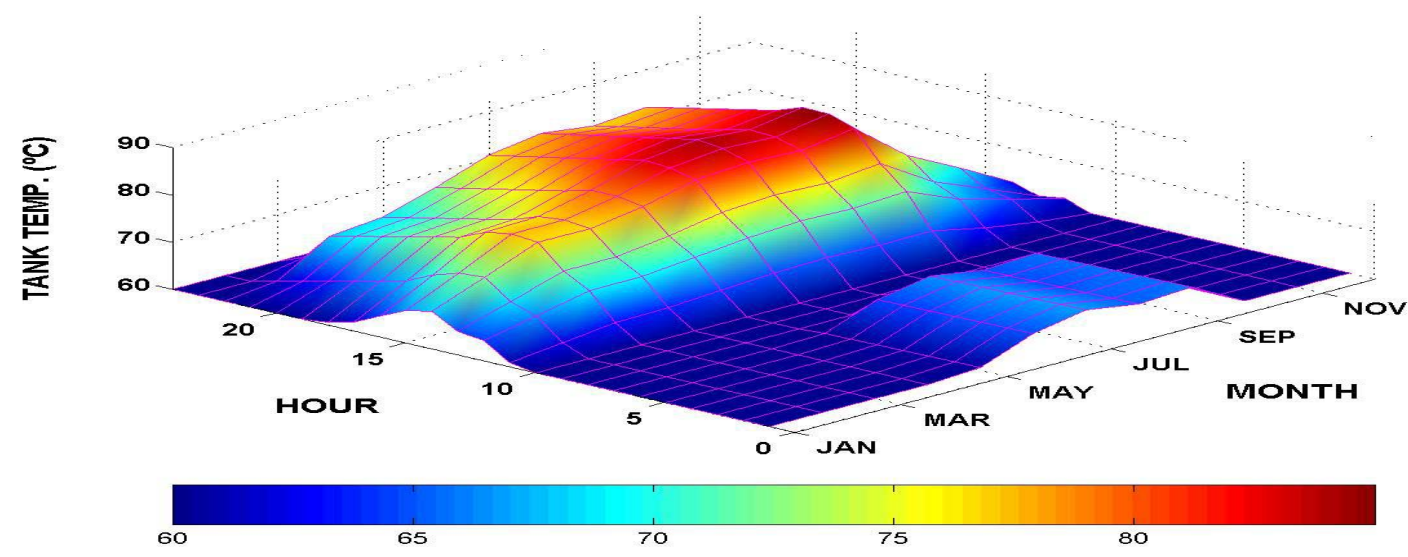

Fig. 7. Tank temperatures. Parameters: $8 \mathrm{~m}^{2}$ solar collector, 1501 storage tank, colector case (1) and variable consumption profile

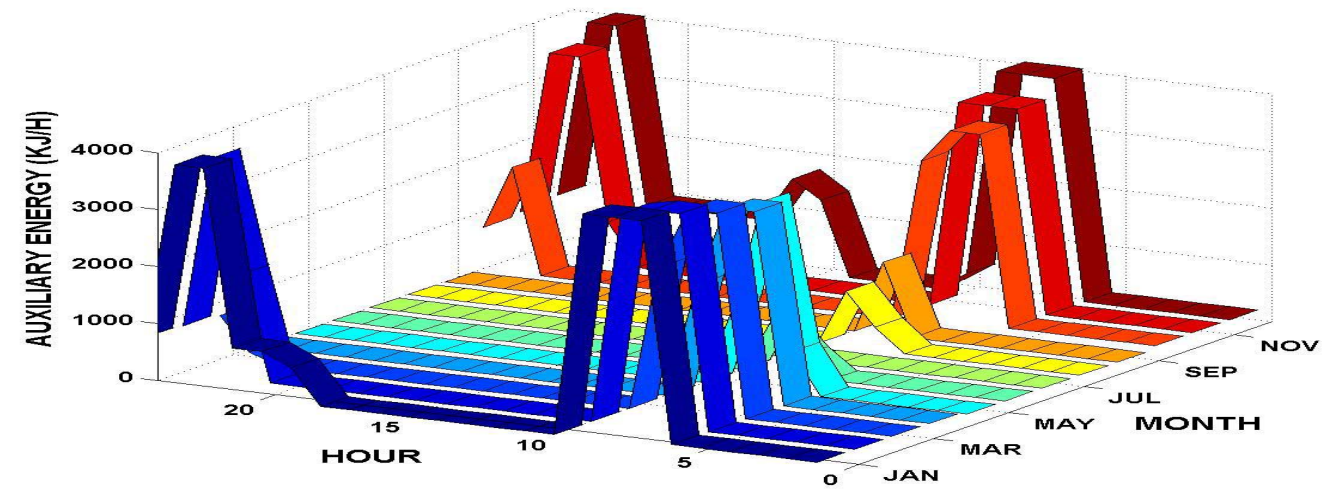

Fig. 8. Auxiliary energy. Identical parameters than Fig. 7

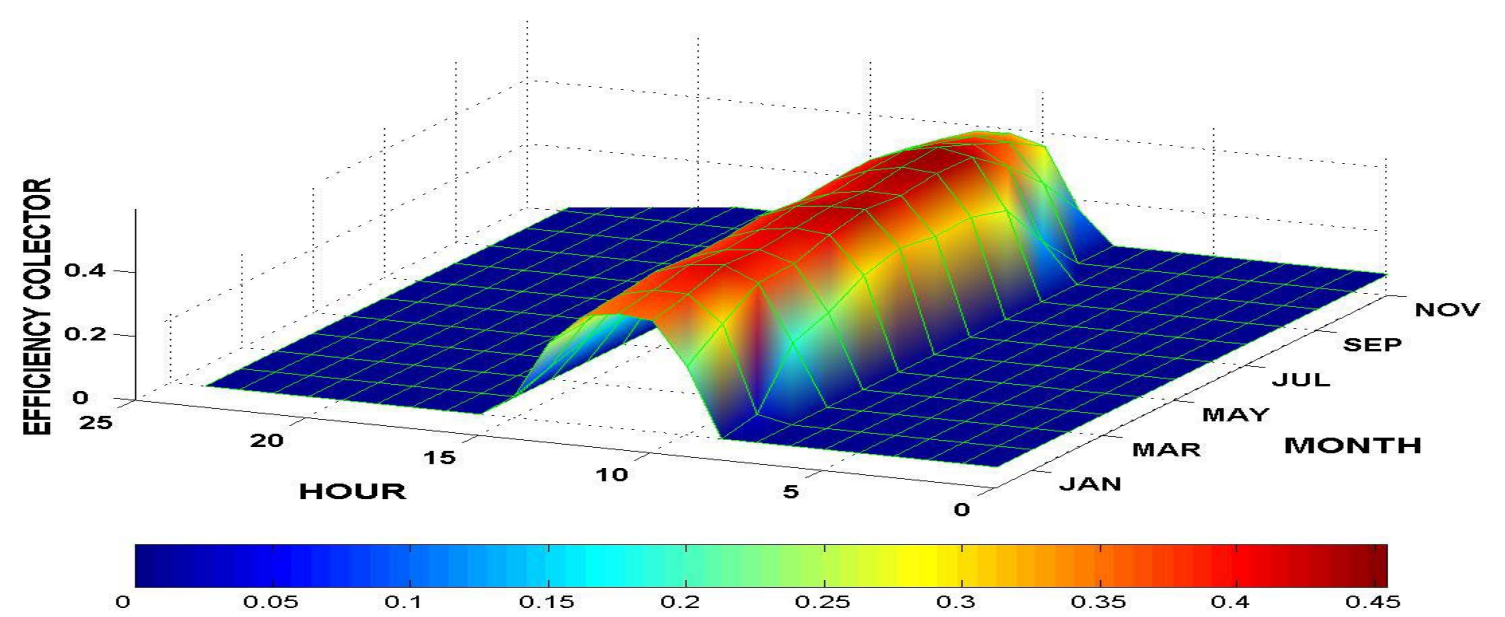

Fig. 9. Hourly efficiency collector. Identical parameters than Fig. 7 
Figures 10 and 11 shows annual solar fraction as a function of the volume storage tank for 6 and $8 \mathrm{~m}^{2}$ collectors area, respectively.

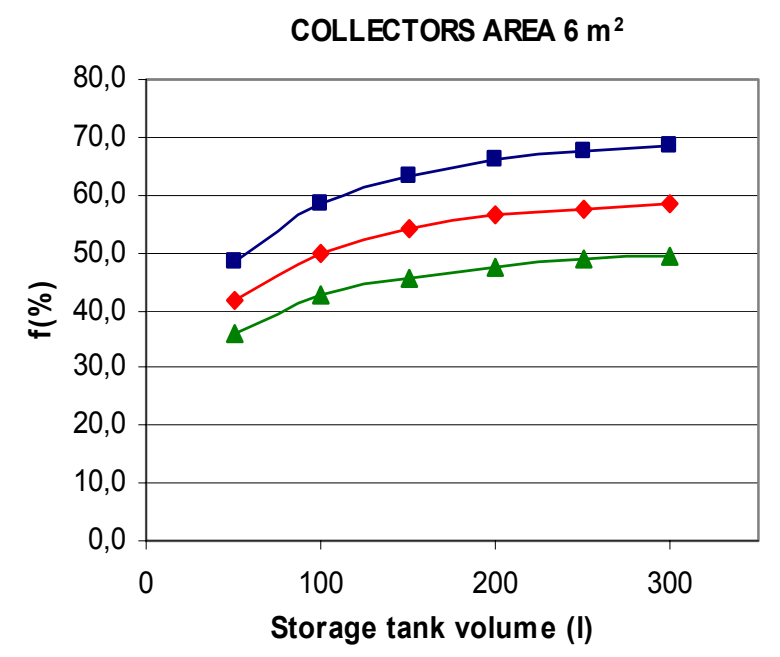

$\multimap \mathrm{b}=3.5 \mathrm{~W} / \mathrm{m} 2^{\circ} \mathrm{C} \longrightarrow \mathrm{b}=4 \mathrm{~W} / \mathrm{m} 2^{\circ} \mathrm{C} \longrightarrow \mathrm{b}=4.5 \mathrm{~W} / \mathrm{m} 2^{\circ} \mathrm{C}$

Fig. 10. Solar Fraction as function of the volume storage tank. Collector area $6 \mathrm{~m}^{2}$

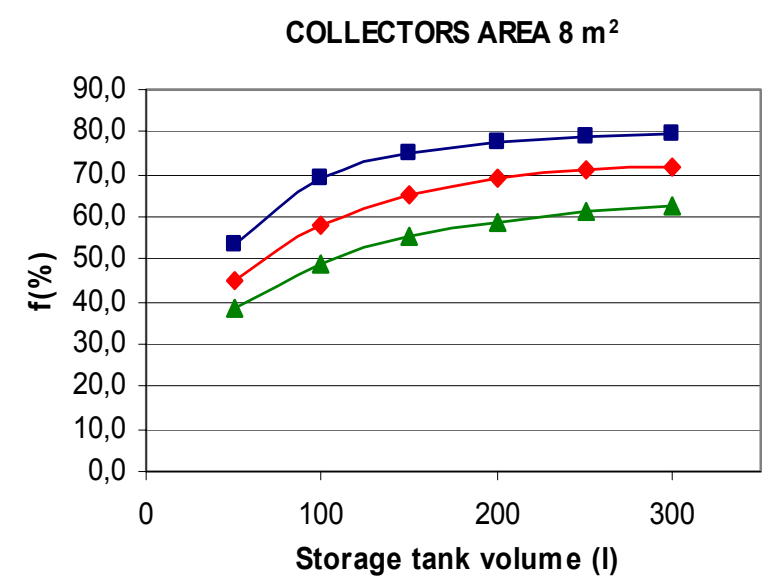

$\longrightarrow \mathrm{b}=3.5 \mathrm{~W} / \mathrm{m} 2^{\circ} \mathrm{C} \longrightarrow \mathrm{b}=4 \mathrm{~W} / \mathrm{m} 2^{\circ} \mathrm{C} \longrightarrow \mathrm{b}=4.5 \mathrm{~W} / \mathrm{m} 2^{\circ} \mathrm{C}$

Fig. 11. Solar Fraction as function of the volume storage tank. Collector area $8 \mathrm{~m}^{2}$

In both figures it's observed the effects of storage volume on solar fraction. Solar fraction increases when increases storage volume. This increases are relatively high for small volumes and moderates for large volumes, remains nearly constant for bigger capacities in all simulation independently of the collector cases considered .
Although the results presented in this paper have not been experimentally verified, these are considered by the authors as valid for similar real systems operated in Santander.

\section{Conclusions}

The results of this investigation may be used to design a solar collector system, and to operate already designed systems, properly.

The results for a number of designs with different storage tank volumes indicate that the systems with greater storage volume yield higher solar fraction. However, when the storage volume is larger, the solar fraction is less sensitive to a variation of the operation parameters.

To select a system with optimum storage volume, an economic analysis should be additionally performed that takes into account in addition to the initial investment required the money saved due to reduced fuel or electricity usage.

The present model can be viewed as a new simulation model, which can be used for parametric analysis of domestic water heating systems.

\section{Nomenclature}

a Collector optical losses

$b \quad$ Collector thermal losses

$S_{C} \quad$ Solar collector absorber surface area

$C p \quad$ Specific heat

$F_{R} \quad$ Collector efficiency factor

$f \quad$ Yearly solar fraction

$M_{\text {Tank }} \quad$ Water mass in the tank

$\dot{m} \quad$ Circulated water mass-flow rate

$\dot{m}_{\text {Load }}$ Consumption water mass-flow rate

$\dot{m}_{\text {Tank }}$ Tank circulated water mass-flow rate

I Solar energy flux per unit surface area of the solar collector absorber

$P \quad$ Head exchanger efficiency

$Q_{\text {Aux }} \quad$ Auxiliary energy

$\dot{Q}_{\text {Collec }}$ Collector energy gain

$\dot{Q}_{\text {Load }} \quad$ Load rate energy

$\dot{Q}_{\text {loss }} \quad$ Tank loss rate energy

$\dot{Q}_{\text {removal }}$ Removal tank rate energy

$S_{C} \quad$ Solar collector absorber surface area

$S_{T} \quad$ Tank surface area

$T_{a m b} \quad$ Ambient temperature

$T_{a m b}$, Surrounding ambient tank temperature

$T_{C i n} \quad$ Circulated water temperature at the solar collector entrance

$T_{\text {Cout }} \quad$ Circulated water temperature at the solar collector exit

$T_{\text {Load }} \quad$ Required temperature of the DHW

$T_{\text {Mwater }} \quad$ Mains water temperature

$T_{T} \quad$ Water tank temperature 
$U_{C} \quad$ Solar collector total heat loss coefficient

$U_{T} \quad$ Tank total heat loss coefficient

$V \quad$ Storage tank volume

$\alpha \quad$ Absorptance of solar collector

$\tau \quad$ Transmittance of solar collector cover

\section{References}

[1] Comakli O, Bayramoglu M, Kaygusuz K. "A thermodynamic model of a solar assisted heat pump system with energy storage". Solar Energy 1996;56:485-492.

[2] Shariah AM, Lof GOG. "The optimisation of tank-volumeto-collector-area ratio for a thermosyphon solar water heater". Renewable Energy 1996;7:289-300.

[3] Duffie JA, Beckman WA. Solar engineering of thermal processes. 2nd ed. New York: Wiley, 1991.

[4] Prieto J.I., "Fundamentos y Aplicaciones de la Energía Solar Térmica", Oviedo University,1998. 